\title{
Incidence and clinical importance of perioperative histamine release: randomised study of volume loading and antihistamines after induction of anaesthesia
}

\author{
Wilfried Lorenz, Dorothea Duda, Wolfgang Dick, Helmut Sitter, Alfred Doenicke, Andrew Black, Doris Weber, \\ Henrik Menke, Benno Stinner, Theodor Junginger, Matthias Rothmund, Christian Ohmann, Michael J R Healy, \\ and the Trial Group Mainz / Marburg
}

\section{Summary}

Although histamine release is recognised as a common event during anaesthesia and surgery, few clinicians judge the resultant cardiorespiratory disturbances serious enough to warrant prophylaxis with antihistamines. We have assessed the incidence and importance of histamine release in a randomised $2 \times 2$ factorial study.

240 patients representing a routine throughput of major general surgery were studied during a standardised induction of anaesthesia and preoperative loading of the circulation with either Ringer solution or Haemaccel-35, with or without antihistamine prophylaxis with dimetindene $\left(H_{1}\right)$ plus cimetidine $\left(\mathrm{H}_{2}\right)$. Cardiorespiratory disturbances were graded as detectable, clinically relevant, or life-threatening from observers' records of the anaesthesia and the actions taken by the anaesthetists. Disturbances that were accompanied by significant rises in plasma histamine were further designated histamine-related, and those that were not were designated histamine-unrelated. Anaesthetists, observers, and designators were blinded to whether or not the patients had received antihistamines and to which solution was used for circulatory volume loading.

Clinically relevant or life-threatening histamine-related disturbances occurred in $8 \%$ of the patients who after induction of anaesthesia received Ringer without antihistamines, in $26 \%$ of those who received Haemaccel without antihistamines, and in $2 \%$ or less of those who received antihistamines $(p \leqslant 0$ 0001). There were 4 life-threatening histamine-related disturbances, all in patients who received Haemaccel without antihistamines $(p<001)$. Histamineunrelated disturbances occurred in $16 \%$ overall, with no

Institute of Theoretical Surgery (Prof W Lorenz MD, H Sitter Dipl Math, D Weber), Department of General Surgery (Prof M Rothmund MD, B Stınner MD), Philipps University, Marburg; Clinic of Anaestheslology (D Duda MD, Prof W Dick MD) and Clinic of General Surgery (H Menke MD, Prof Th Junginger MD), Johannes Gutenberg University, Malnz; Institute of Anaesthesiology, Ludwig Maximillan University of Munich (Prof A Doenicke MD); Theoretical Surgeny Unit, Department of Surgery, University of Düsseldorf (Ch Ohmann PhD); Department of Anaesthesia, Bristol Royal Infirmary (A Black MD); and Departments of Medical Statistics and Epidemiology, London School of Hyglene and Troplcal Medicine (Prof M J R Healy MA)

Correspondence to: Prof W Lorenz, Zentrum für Operatıve Medizin I, Theoretısche Chırurgie, 35033 Marburg, Germany obvious effect of Haemaccel or antihistamines. The histaminerelated disturbances under anaesthesia were remarkable for their severity (even with small rises in histamine concentrations), for the prevalence of bradycardia, and for the absence of skin signs. Their likelihood and severity were increased in patients with tumours.

The results of the trial make a case for routine prophylaxis with antihistamines as part of anaesthetic management.

Lancet 1994; 343: 933-40

See Commentary page 929

\section{Introduction}

Clinicians recognise that histamine is released quite commonly during anaesthesia and surgery, ${ }^{1-4}$ and occasionally has ill-effects. However, when some alarming and life-threatening complication develops during a routine procedure, they will seldom blame histamine. ${ }^{5}$ Moreover, the usual view is that such events are too rare to warrant either routine or selective use of antihistamine as prophylaxis 6 -despite documentation of incidences of histamine-related disturbances of up to $30 \%,{ }^{\circ}$ some of them very severe. ${ }^{8}$

The classic requirements ${ }^{9}$ for establishing that a putative mediator substance is responsible for an observed disturbance are (i) that the disturbance is brought about by giving the substance, (ii) that the substance is released when the disturbance occurs naturally, and (iii) that a specific antagonist of the substance prevents the disturbance from occurring. ${ }^{10}$ As early as 1929 , histamine was noted to imitate features of the untoward events seen during anaesthesia, surgery, trauma and sepsis; ${ }^{11}$ and other such substances include serotonin, various kinins, eicosanoids, cytokines, and nitric oxide. However, the classic tests for implicating putative mediators have still not been applied to histamine in a routine clinical setting, despite the availability of the means to do so-namely, reliable and sensitive assays, ${ }^{12}$ powerful and specific antagonists of the actions of histamine on two of its most important receptors $\left(H_{1}\right.$ and $\mathrm{H}_{2}$ ) in the cardiovascular and respiratory systems, ${ }^{13}$ and the methodology of the controlled clinical trial. ${ }^{14}$

We have completed a randomised double-blind controlled clinical trial of the effects of prophylaxis against possible effects of histamine release during anaesthesia, surgery, and the subsequent 30 days in a representative sample of patients undergoing routine major general surgery under standardised but typical general anaesthesia. Dimetindene maleate was used to block the effects of 
Total electlve operations Dec 1988-Sept 1991

First 2 patients in the 3 operating theatres each weekday

Patients excluded by escape crlteria

Holidays on weekdays

Failure of measurement capabilities

Anaesthetist's errors in applying exclusion rules

Anaesthetist's preference for "personal" induction

Patient not from general surgery clinic

Absence of written consent by patient

Private patients (excluded by surgeon)

Emergency cases interrupting

No general anaesthetic

Not 1st operation during study period

Age less than $18 \mathrm{yr}$

Peptic Gl tract disease with $\mathrm{H}_{2}$ antagonist

Transplantation/bypass

ASA class $>3$

Allergy or asthma

Patients specifically ellglble for study

Study sample selected randomly

Table 1: Eligibility of study patients from clinlc population

histamine at $\mathrm{H}_{1}$ receptors and cimetidine the effects at $\mathrm{H}_{2}$ receptors. ${ }^{78}$ This report is restricted to results obtained between the induction of anaesthesia and the start of surgery. During this time the patients received circulatory volume loading either with Ringer solution, which releases virtually no histamine, ${ }^{15}$ or with Haemaccel-35, with which histamine release is thought to be appreciable but modest ${ }^{16}$ - comparable with that induced by many other drugs used in anaesthesia and surgery. ${ }^{1-4}$

\section{Methods}

The study was approved by the institutional review board in Marburg and Mainz after extensive published discussion of its intended methods ${ }^{17,18}$ and a pilot study of its feasibility. Only the main features of the methods are described below.

The defined population from which the sample was selected comprised the 4230 patients who underwent elective abdominal, oncological, endocrine, vascular, or thoracic surgery in three operating theatres in Mainz between December, 1988, and October, 1991. The inclusion and exclusion criteria listed in table 1 and the algorithm for selecting patients were specified and published in advance. ${ }^{17}$ By a random number allocation from 1 to 6 to the patients of each day, the first sample of 3339 was reduced to 839 , and the patient with the lowest remaining random number in the nominal block of 6 was selected as the one patient for the next morning for operation until 240 had been recruited. This sample size was designed to provide a power of 0.8 at a significance level of $2 \alpha=0.05$ to detect a reduction of $30 \%$ in the primary endpoint variable-histamine-related cardiorespiratory disturbance.

The 240 patients were allocated randomly to four treatment groups of 60 patients each, for a double-blind $2 \times 2$ factorial study of the effects of antihistamine $\left(\operatorname{anti}-\mathrm{H}_{1} \mathrm{H}_{2}\right.$ ) prophylaxis and volume loading with Haemaccel. The four treatment groups were placeboRinger, placebo-Haemaccel, antihistamines-Ringer, and antihistamines-Haemaccel. The treatments were prepared by personnel otherwise uninvolved with the study, and were administered to the patients by personnel who were kept ignorant of their nature.

\section{Clinical conduct of the presurgical period}

The routine anaesthetist was responsible for anaesthesia but was accompanied by an observer (likewise an anaesthetist) who maintained a parallel, independent, anaesthetic record that included the responses of the anaesthetist to clinical events. Blood samples for histamine measurement were taken and processed by two technicians.

The scheme for the presurgical part of the study is shown in figure 1 . The patients arrived in the operating theatre an hour or so after oral premedication with benzodiazepines and whatever other medication (antithrombotic, antihypertensive, \&c) had been prescribed. This was carefully recorded. Two peripheral venous cannulae (one for giving drugs and fluids, the other in the opposite arm for sampling) were inserted half an hour before the start of the anaesthetic induction sequence. Next, the antihistamine prophylaxis or placebo was infused over 3-5 min. It consisted of

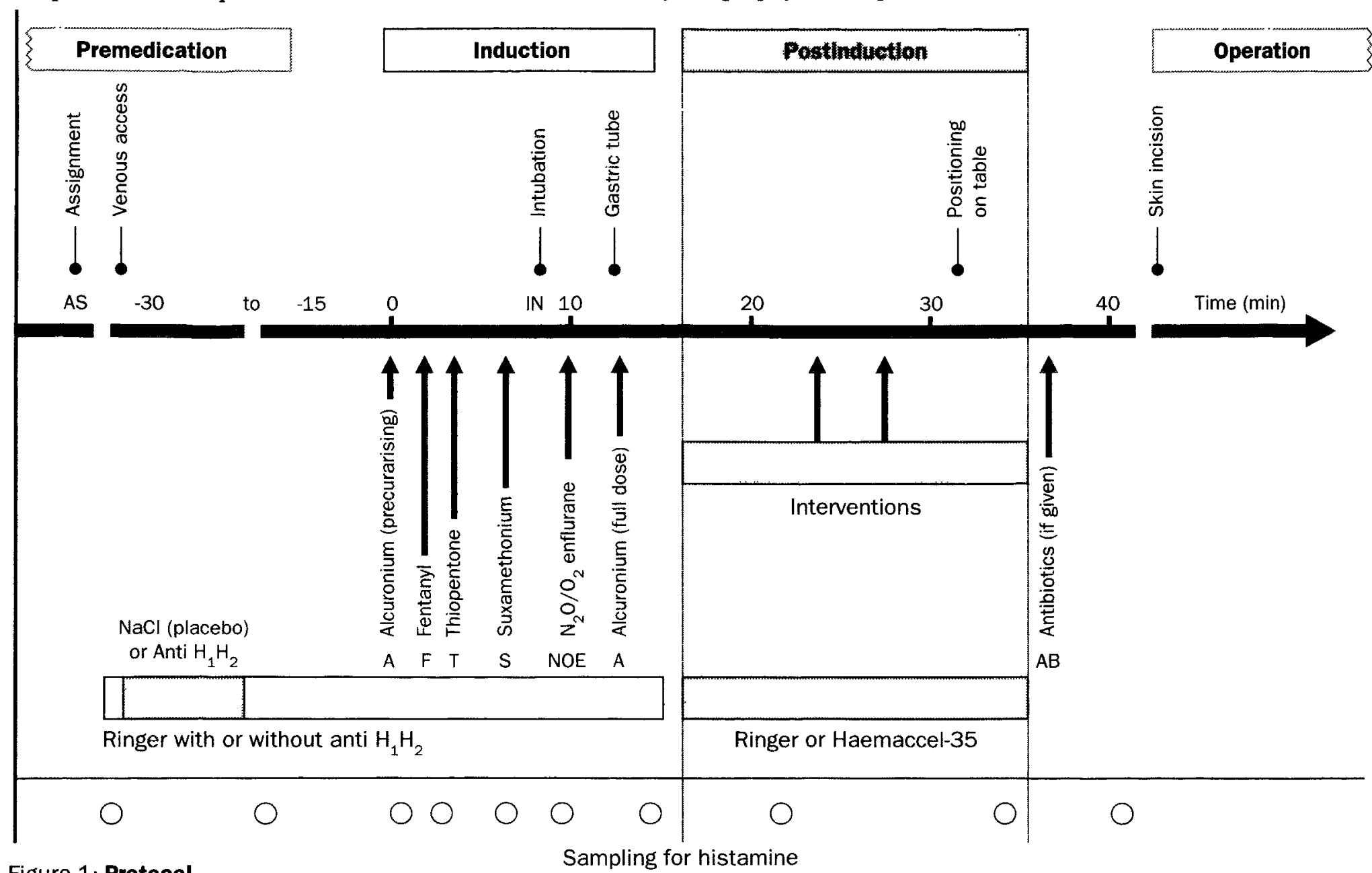

Figure 1: Protocol

Sampling for histamine

Anti $\mathrm{H}_{1} \mathrm{H}_{2}=$ dimetindene maleate + cimetidine. Shaded bars= parts of routine anaesthesia and preparatıon for surgery which were influenced by the controlled trial. 


\begin{tabular}{|c|c|}
\hline Disturbances & Actlons taken \\
\hline Cardlovascular & $\begin{array}{l}\text { Vasopressor } \\
\text { Volume loading-faster and/or more } \\
\text { Head down position } \\
\text { Reduction of enflurane } \\
\text { Atropine } \\
\text { Miscellaneous (eg, orciprenaline, tracheal stımulation) as recorded }\end{array}$ \\
\hline Resplratory & $\begin{array}{l}\text { Hyperventilation (volume, oxygen) } \\
\text { Fenoterol inhalation } \\
\text { Theophylline } \\
\text { Endotracheal suction } \\
\text { Miscellaneous (as recorded) }\end{array}$ \\
\hline Allerglc & $\begin{array}{l}\mathrm{H}_{1}-+\mathrm{H}_{2} \text {-antihistamınes } \\
\text { Corticosteroids } \\
\text { Theophylline } \\
\text { Miscellaneous (as recorded) }\end{array}$ \\
\hline Emergency & Miscellaneous (as recorded) \\
\hline
\end{tabular}

Table 2: Actions of the responsible anaesthetist

either an ampoule each of dimetindene maleate $(4 \mathrm{mg})$ and cimetidine $(200 \mathrm{mg})$ or two ampoules of placebo for each $45 \mathrm{~kg}$ of body weight, made up in $100 \mathrm{~mL} 0.9 \% \mathrm{NaCl}$ solution. The dose corresponded to $0.1 \mathrm{mg} / \mathrm{kg}$ dimetindene and $5 \mathrm{mg} / \mathrm{kg}$ cimetidine. It was added to an infusion of $500 \mathrm{~mL}$ Ringer solution which was started just before.

Anaesthesia was induced 10-15 min later (starting at time zero, figure 1) by a standardised sequence of drugs consisting of a pre-curarising dose of alcuronium $0.03 \mathrm{mg} / \mathrm{kg}$ (as prophylaxis against fasciculations), fentanyl $2.5 \mu \mathrm{g} / \mathrm{kg}$, thiopentone $4-6 \mathrm{mg} / \mathrm{kg}$, suxamethonium $1.5 \mathrm{mg} / \mathrm{kg}$, and, after intubation of the trachea and introduction of $\mathrm{N}_{2} \mathrm{O} / \mathrm{O}_{2}$ and enflurane, a fully relaxing dose of alcuronium $0 \cdot 1 \mathrm{mg} / \mathrm{kg}$. The drugs were given at intervals of $1-3 \mathrm{~min}$ (figure 1), to allow time to take $8 \mathrm{~mL}$ samples of blood between the drug applications (to identify any histamine release). ${ }^{7,10}$ The last sample of the induction period was $3 \mathrm{~min}^{19}$ after the full dose of alcuronium, and the next $20 \mathrm{~min}$ was designated the postinduction period.

During this time, the circulation was volume-loaded with 500 $\mathrm{mL}$ of either Ringer or Haemaccel-35, randomly allocated. The volume expanders were contained in an opaque silvered container and giving-set. During the volume loading, any other necessary preparations for surgery were carried out, including positioning on the operating table. Just before the start of surgery, prophylactic antibiotics (usually cefuroxime and metronidazole) were given to about half of the patients.

The anaesthetist responsible for the case undertook the routine monitoring for anaesthesia, including electrocardiogram for arrhythmias and ST depression, automated noninvasive blood pressure monitoring (Dinamap), breathing rate, expired tidal and minute volumes and airway pressures (Dräger), and pulse oximetry (Criticon) as well as the normal clinical observations for cutaneous signs (erythema, wheals, and oedema) and bronchospasm. The observer kept a parallel record not only of the observations but also of the responses of the anaesthetist in terms of the items listed in table 2. Before the start of surgery, the observer-anaesthetist was asked in the protocol to guess the treatment group to which the patient had been allocated. This was to assess the effectiveness or otherwise of the blinding to treatment in each of the groups.

\section{Assessing clinical events and interventions}

The observers' records were compared with predetermined endpoints ${ }^{17,20-22}$ by scrutineers who were kept ignorant of the treatment group. Cardiorespiratory disturbances with or without cutaneous signs, respiratory difficulty, bronchospasm, or cyanosis were graded as: (1) "detectable" if heart rate changed by more than $10 / \mathrm{min}$ or blood pressure changed by more than $10 \mathrm{~mm} \mathrm{Hg}^{, 23}$ (ii) "clinically relevant" if they prompted the anaesthetist into one of the actions listed in table 2, or (iii) "life threatening" if they prompted emergency measures including unscheduled admission to an intensive care unit. Tachycardia, bradycardia, and hypotension were defined as changes in heart rate or blood pressure rather than as absolute values.

\begin{tabular}{|c|c|c|c|c|}
\hline Characteristics & $\begin{array}{l}\text { Placebo }+ \\
\text { Ringer } \\
(\mathbf{n}=\mathbf{5 9})\end{array}$ & $\begin{array}{l}\text { Placebo }+ \\
\text { Haemaccel } \\
(n=57)\end{array}$ & $\begin{array}{l}\text { Antl } \mathrm{H}_{2} \mathrm{H}_{2}+ \\
\text { Ringer } \\
(n=59)\end{array}$ & $\begin{array}{l}\text { Anti } \mathrm{H}_{\mathbf{1}} \mathrm{H}_{2}+ \\
\text { Haemaccel } \\
(\mathrm{n}=\mathbf{5 6})\end{array}$ \\
\hline Age yr; medlan (range) & $\overline{56(21-80)}$ & $\overline{52(19-77)}$ & $49(19-78)$ & $51(20-78)$ \\
\hline Male $(\%)$ & 56 & 47 & 56 & 48 \\
\hline ASA class $1,2,3(\%)^{*}$ & $14,59,27$ & $14,56,30$ & $25,48,27$ & $11,76,13$ \\
\hline \multicolumn{5}{|c|}{ Primary disease class (\%) } \\
\hline Malıgnant disease & 24 & 35 & 29 & 34 \\
\hline Local lesion only & 27 & 30 & 34 & 25 \\
\hline EPA diseasest & 49 & 35 & 37 & 41 \\
\hline \multicolumn{5}{|l|}{ Concomitant disease (\%) } \\
\hline Heart & 25 & 35 & 17 & 27 \\
\hline Vascular system & 44 & 39 & 34 & 32 \\
\hline Respiratory tract & 15 & 21 & 15 & 13 \\
\hline Kidney, urinary tract & 12 & 5 & 5 & 11 \\
\hline Metabolism & 31 & 26 & 24 & 23 \\
\hline Liver, now or formerly & 31 & 23 & 29 & 32 \\
\hline $\begin{array}{l}\text { Previous operations, } \\
\text { none }(\%)\end{array}$ & 14 & 28 & 32 & 16 \\
\hline $\begin{array}{l}\text { Operations in last } 2 \\
\text { yr }(\%)\end{array}$ & 22 & 23 & 25 & 20 \\
\hline $\begin{array}{l}\text { Operations in Iffetime, } \\
\text { median (range) }\end{array}$ & $2(0-13)$ & $2(0-6)$ & $1(0-15)$ & $1(0-5)$ \\
\hline
\end{tabular}

*Assessed by observer-anaesthetist.

tEndocrıne, proliferative (eg, Crohn's disease), or atherosclerotıc diseases.

Table 3: Baseline patient characteristics

The scrutineers (one study leader, one observer, one information technologist) completed the first classification of disturbances without knowing the contemporaneous plasma histamine concentrations. These were measured by a standard fluorometricfluoroenzymatic assay ${ }^{24}$ with a detection limit of $0.01 \mathrm{ng} / \mathrm{mL}$. This was subjected to continual intensive quality control against both internal $1^{17,24}$ and external standards. ${ }^{12}$ An "episode of histamine release" was defined as a rise of more than three times the coefficient of variation of the measurement: this amounted to a $200 \%$ rise from values between 0.06 and $0.24 \mathrm{ng} / \mathrm{mL}$ and a $40 \%$ rise from values greater than $0.24 \mathrm{ng} / \mathrm{mL} .^{20}$ The scrutineers classified their graded cardiorespiratory disturbances further as "histaminerelated" or "histamine-unrelated", depending on whether they were found to have coincided with episodes of histamine release.

Reliable and unbiased assessment and designation of the clinical events was clearly crucial to the interpretation of the study. Scrupulous attention was paid to this during design, conduct, and data analysis of the study to ensure: (i) blindness-to-treatment of the anaesthetists, observers, and scrutineers, (ii) strict adherence to predetermined criteria ${ }^{20-23}$ for classifying the observed disturbances by the scrutineers, and (iii) double-checking by an independent advisory group of the scrutineers' classifications to assess repeatability (advisory group).

\section{Statistical analysis}

The primary objective of the study was to compare the incidence of histamine-related reactions in the four treatment groups. These nominal data are presented as percentages with $95^{\circ}, 0$ confidence intervals (CI). Interval variables (plasma histamine) are given as medians and ranges. Rates of relative risk are calculated by standard methods. Inferential statistics include chi-square tests and Kruskal-Wallis nonparametric analysis of variance. Logistic regression analysis was undertaken to test for interaction of the two treatment factors in the $2 \times 2$ factorial design and to allow for imbalances in risk factors (table 3 ) additional to the allocated treatments. The first model included all independent variables,

\begin{tabular}{lcll}
\hline Prognostic factor & Total population $(\mathbf{n}=\mathbf{4 2 3 0})$ & & Trial patients $(\mathbf{n}=\mathbf{2 4 0})$ \\
\cline { 1 - 2 } Males & $522 \%$ & & $48 \%$ \\
Age, median (range) & $604(15-93)$ & $52(19-80)$ \\
ASA class 1 & $35 \%$ & $108 \%$ \\
2 & $415 \%$ & $538 \%$ \\
3 & $423 \%$ & $355 \%$ \\
Tumours as primary disease & $315 \%$ & $300 \%$ \\
\hline
\end{tabular}

ASA class assessed by routine anaesthetist

Table 4: Comparison of study sample with clinic population 
PL BP HR

$\mathrm{ng} / \mathrm{mL} \quad \mathrm{mm} \mathrm{Hg}$ beats/min

Blood pressure $\quad \longrightarrow$ Heart rate

Plasma histamine
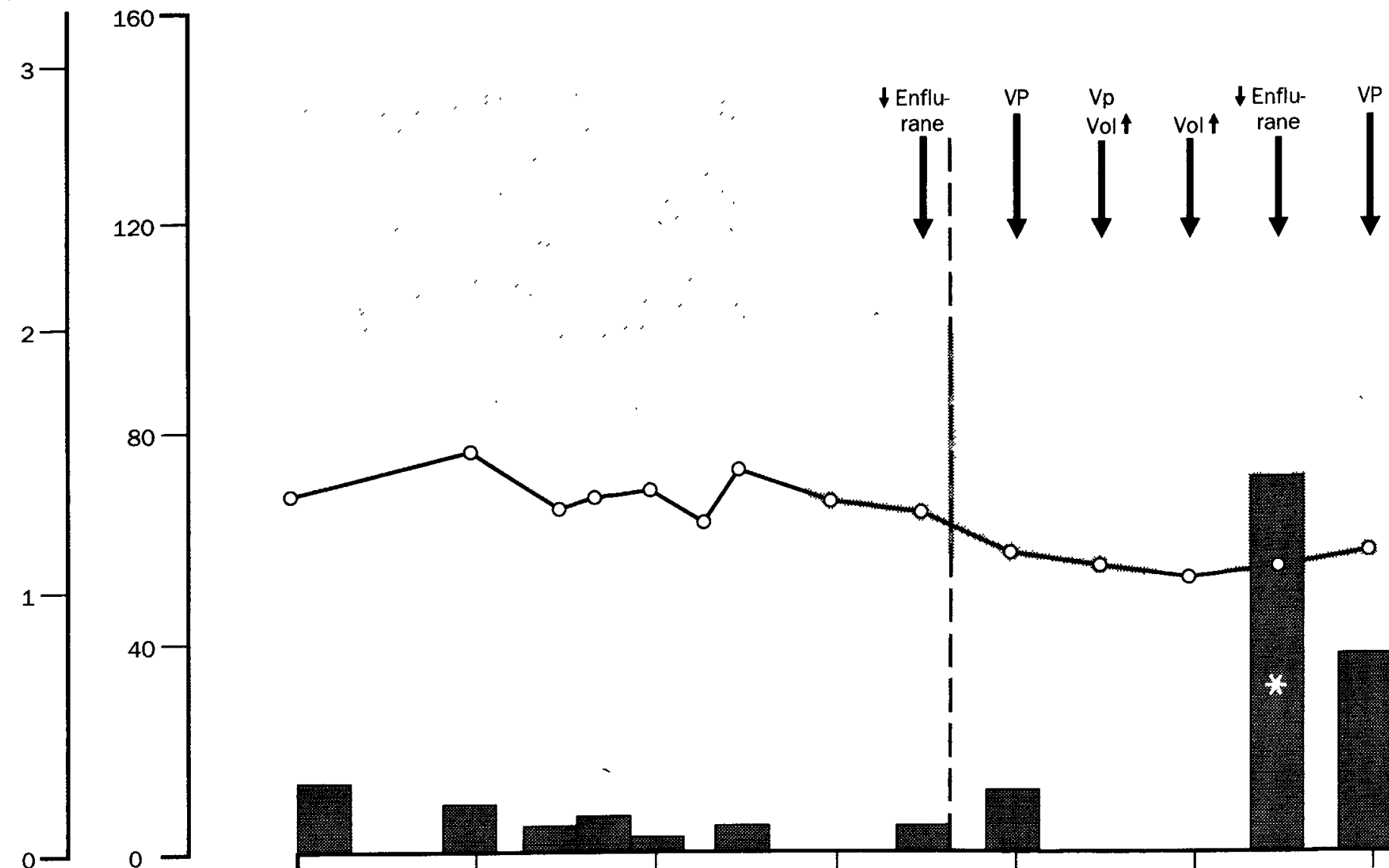

0

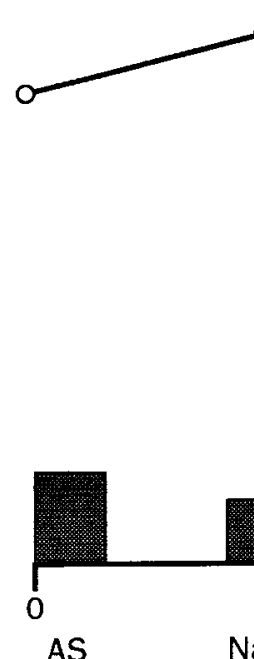

AS

$\underline{\mathrm{NaCl}}$

A $F$ T

NOE

Patient no 147

59 yr, ASA 2, Abdominal hernia

Time (min)

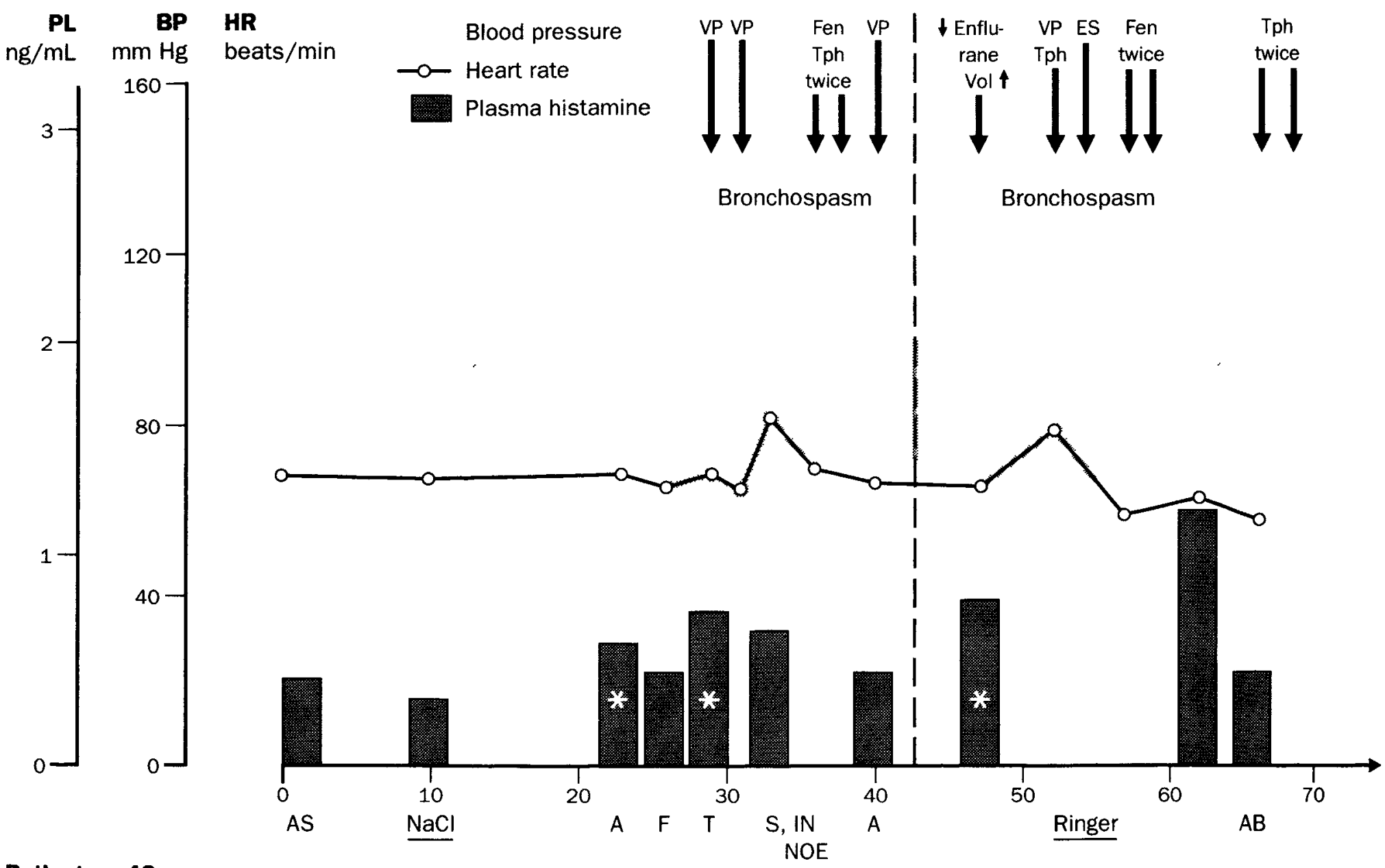

Patient no 42

63 yr, ASA 2, Arterial embolism

Time (min)

Figure 2: Postinduction cardiorespiratory disturbances related to histamine in Haemaccel and Ringer group: multiple interventions $\mathrm{PL}=$ plasma histamine, $\mathrm{BP}=$ blood pressure, $\mathrm{HR}=$ heart rate.

$(\text { a })^{*}=$ histamine release, vertical dashes $=$ start of postinduction period, vol $\uparrow=$ increased or accelerated volume loading, $\downarrow$ enflurane $=$ reduction in enflurane concentration.

(b) $\mathrm{Tph}=$ theophylline, Fen $=$ fenoterol, ES $=$ endotracheal suction, $\mathrm{VP}=$ vasopressor. Additional abbreviations in 2a, 2b are explained in figure 1. 
and the second used a stepwise forward selection including treatment and the set of variables in table 3 with coding of nominal data as $2 / 1$ for present/absent and $\alpha=0.2$ for entry of a covariate into the model. The phi-coefficient ${ }^{17}$ method was used to estimate the probability that the extent of agreement between the observers' opinions and the true treatment could have arisen from random guesswork in each treatment group. The data were analysed with SAS and Nanostat software on an 486 IBM PC PS/II.

\section{Results}

The 240 patients in the study were reasonably representative of the designated parent population in several important respects (table 4), despite the exclusion of patients of American Society of Anesthetists (ASA) grade $>3$ and those with a history of allergy or asthma. Table 3 gives baseline information on patients in the four treatment groups. Randomisation was fair; ${ }^{25}$ chi-square tests $(\mathrm{df}=3$ ) were not significant for any single variable and forward stepwise logistic regression modelling identified only malignant disease as a risk factor for clinically relevant histamine-related disturbances (odds ratio 1.99 after allowance for treatment differences). 9 patients $(4 \%)$ did not complete the study: in 1, anaesthesia was interrupted to make way for an emergency case; 1 arrived in the induction room with tachyarrhythmia; in 1 case the observeranaesthetist was taken ill; in 2 blood sampling was impossible; 3 patients were premedicated in error with promethazine; and 1 patient changed his mind at the last moment about participating. There was no difference between treatment groups in the proportions of responsible (scheduled) anaesthetists $(n=59)$ or observers $(n=4)$ of different seniority and experience. Blindness was not uniformly achieved across the groups, but fortunately there were no significant differences with regard to interventions in the most important groups (clinical relevance)-for placebo vs anti- $\mathrm{H}_{1} \mathrm{H}_{2}$ prophylaxis in all four groups (phi-coefficient $2 \cdot 2 \%$ ) and for volume loading in the two Haemaccel groups $(11 \cdot 6 \%)$. The observer-anaesthetists did identify Ringer solution significantly more often than expected by chance $(36.5 \%$, chi-square $p<0.001)$, presumably because blood pressure responded less promptly to Ringer than to Haemaccel.

Histamine-related cardiorespiratory disturbances occurred with remarkably low plasma histamine levels. Figure 2 illustrates events in 2 patients who received no antihistamine prophylaxis. In patient 147 no histamine release was detectable by our predetermined criteria until 20 min after the start of volume loading with Haemaccel. Although induction of anaesthesia had itself caused hypotension that prompted a reduction in enflurane concentration, the hypotension persisted despite the volume loading and six other interventions. The maximum rise in histamine concentration was only $1.3 \mathrm{ng} / \mathrm{mL}$. In patient 42 there was a small histamine rise after the pre-curarising alcuronium and another after thiopentone. The associated clinical events required 7 interventions by the anaesthetist to deal with hypotension and bronchospasm. The histamine concentrations fell rapidly (as expected from its pharmacokinetics ${ }^{23}$ ) but rose again soon after the start of the Ringer infusion, with accompanying bronchospasm; six further corrective interventions were required. Again the maximum increase in histamine concentration was modest.

Episodes of histamine release accompanied between 13 and $16^{\circ} \%$ of the administrations of each drug in the induction sequence, and occurred during $30^{\circ} \%$ of the

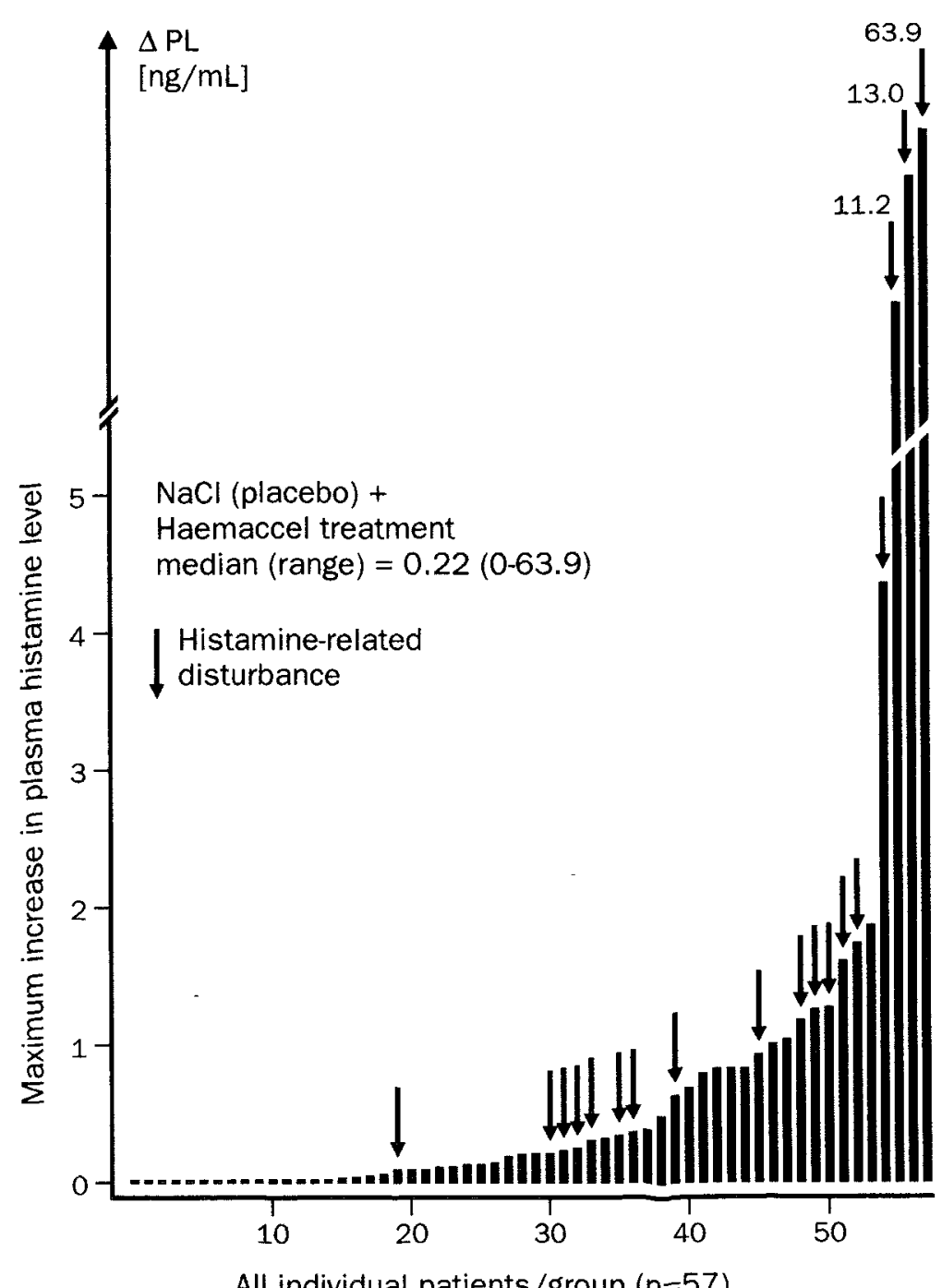

All individual patients/group $(n=57)$

Figure 3: Histamine release in all individual patients after Haemaccel without antihistamines

Arrows indicate patients with cardiorespiratory disturbances related to histamine (all grades of severity).

periods of volume loading. In more than one-third of the patients there were multiple episodes, up to a maximum of four. The plasma histamine increases from baseline in the patients receiving placebo-Ringer ranged between 0 and $11.34 \mathrm{ng} / \mathrm{mL}$, median 0.08 ; in those receiving placeboHaemaccel the range was 0 to $63.9 \mathrm{ng} / \mathrm{mL}$, median 0.22 . In those receiving antihistamines and Ringer the corresponding range was $0-10.66 \mathrm{ng} / \mathrm{mL}$, median 0.04 , and in those receiving antihistamines and Haemaccel it was $0-3.38 \mathrm{ng} / \mathrm{mL}$, median 0.08 . The reduction of histamine release by $50 \%$ (Ringer) and $75 \%$ (Haemaccel) with the antihistamines was significant by Kruskal-Wallis testing $(\mathrm{p}<0.001)$. Figure 3 ranks the maximum increases in plasma histamine concentration from baseline in the

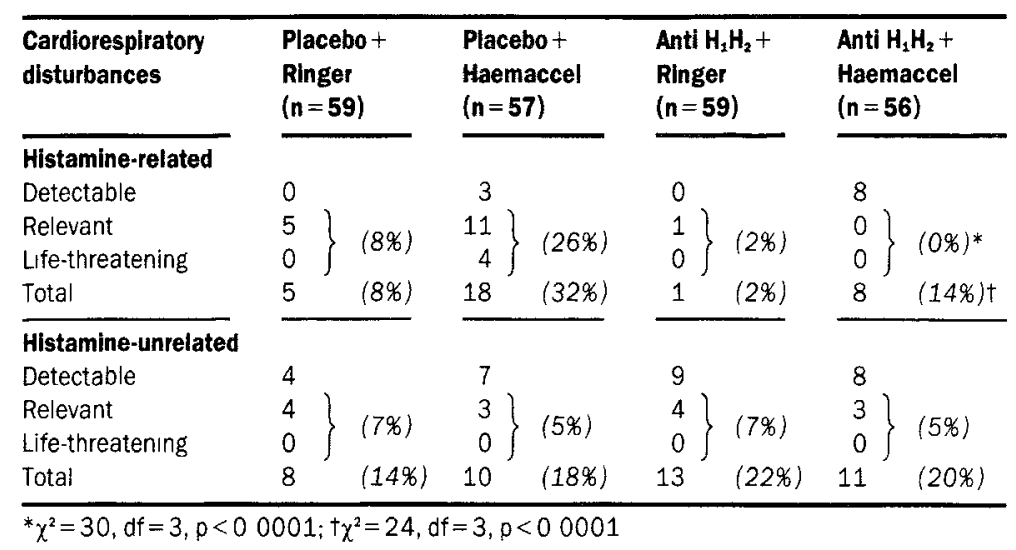
cardiorespiratory disturbances after induction of anaesthesia 
placebo-Haemaccel group and confirms that detectable clinical disturbances could accompany very small increases. However, when the results of the two placebo groups were pooled, the incidence of histamine-related disturbances of all degrees of severity was $12 \%$ with increases in plasma histamine of $0-1 \mathrm{ng} / \mathrm{mL}, 60 \%$ with increases of $1 \cdot 1-2$ $\mathrm{ng} / \mathrm{mL}$, and $83 \%$ with increases greater than $2 \mathrm{ng} / \mathrm{mL}$ ( $p<0.0001, \mathrm{df}=2$, chi-square). Hence, the severity of reactions bore no obvious relation to the change in plasma histamine concentration, though the likelihood of reactions did.

The numbers of cardiorespiratory disturbances, their severity, and their attributions are shown in table 5. The rapid sequence of drug administrations during induction of anaesthesia sometimes made attribution of clinical disturbances uncertain, but it was reliable in the postinduction period. The most striking effect of the antihistamines was the reduction from $26 \%$ (CI 14.6-37.4) to $0 \%$ in the incidence of clinically relevant reactions in those who received Haemaccel. Logistic regression analysis showed no sign of interaction (chi-square $=0.34, \mathrm{df}=1$, $\mathrm{p}<0.5$ ). The effects of Haemaccel vs Ringer (odds ratio $=5 \cdot 85[95 \% \mathrm{CI} 2 \cdot 28-15 \cdot 02])$ and of antihistamines $v s$ placebo (odds ratio $=3 \cdot 12[1 \cdot 34-7 \cdot 28]$ ) were both highly significant. The two treatment factors were additive on the logit scale and the treatment effect of antihistamines was the same in the Ringer as in the Haemaccel group. In sharp contrast, there were no significant differences between treatment groups in the incidence of histamine-unrelated disturbances of any severity.

The 4 patients who had life-threatening disturbancesall in the placebo-Haemaccel group-deserve special mention. The first, aged 75, ASA 3 with gastric cancer, became flushed, severely hypotensive $(40 \mathrm{~mm} \mathrm{Hg})$, and bradycardic $(48 / \mathrm{min}) 10 \mathrm{~min}$ after the start of the Haemaccel infusion and needed emergency treatment (oxygen, fluids, adrenaline, steroids and antihistamines), cancellation of the operation, and 4 days in the intensive care unit. The maximum plasma histamine concentration was $64 \mathrm{ng} / \mathrm{mL}$. The second, aged 51, ASA 2, with pancreatic cancer, behaved similarly to the first patient but spent only 1 day in intensive care, having had a maximum rise in histamine of $13 \cdot 1 \mathrm{ng} / \mathrm{mL}$. The third patient, aged 68 , ASA 3 , undergoing reversal of colostomy for non-malignant disease, required a vasopressor for hypotension and atropine for bradycardia during the Haemaccel infusion, after which two wheals and slight angio-oedema were observed. He had two severe episodes of unexplained hypotension and further haemodynamic instability during the 4 hours of operation and was found to have generalised urticaria at the end. He required emergency treatment and a day of intensive care. The plasma histamine rose from 0.25 $\mathrm{ng} / \mathrm{mL}$ by a maximum of only $0.20 \mathrm{ng} / \mathrm{mL}$ in the period of measurement. The fourth patient, aged 52, ASA 2 with oesophageal cancer, died on the operating table from ventricular fibrillation after repeated and persistent hypotension, resistant to fluid resuscitation and vasopressors and complicated by considerable blood loss. The maximum plasma histamine concentration was 11.5 $\mathrm{ng} / \mathrm{mL} 5 \mathrm{~min}$ after the start of the Haemaccel infusion.

Several features of the untoward reactions were different from conventional descriptions and expectations ("anaphylactoid reactions").1-6 Firstly, the severity of the reactions to Haemaccel in the post-induction period was in striking contrast to the less alarming reactions documented for Haemaccel in unanaesthetised patients. ${ }^{15,16,23}$ Secondly,

\begin{tabular}{|c|c|c|}
\hline \multirow[t]{2}{*}{ - } & \multicolumn{2}{|c|}{ Relevant and iffe-threatening reactlons } \\
\hline & $\begin{array}{l}\text { Placebo groups } \\
(n=116)\end{array}$ & $\begin{array}{l}\text { Antt } \mathrm{H}_{2} \mathrm{H}_{2} \text { groups } \\
(\mathrm{n}=115)\end{array}$ \\
\hline \multicolumn{3}{|c|}{ Mallgnant disease } \\
\hline Yes & $9 / 34(26 \%)$ & $0 / 36(0 \%) \dagger$ \\
\hline No & $11 / 82(13 \%)$ & $1 / 79(1 \%) \dagger$ \\
\hline \multicolumn{3}{|c|}{ Cardiovascular disease } \\
\hline Yes & $12 / 59(20 \%)$ & $0 / 51(0 \%) \dagger$ \\
\hline No & $8 / 57(14 \%)$ & $1 / 64(2 \%) \dagger$ \\
\hline \multicolumn{3}{|c|}{ Histamine release $(\mathrm{ng} / \mathrm{ml})$} \\
\hline $0-10$ & $10 / 100(10 \%)$ & $1 / 105(1 \%) \dagger$ \\
\hline $11-20$ & $5 / 10(50 \%)$ & $0 / 8(0 \%)^{*}$ \\
\hline$>2 \cdot 0$ & $5 / 6(83 \%)$ & $0 / 2(0 \%)^{*}$ \\
\hline All patients & $20 / 116(17 \%)$ & $1 / 115(1 \%) \dagger$ \\
\hline
\end{tabular}

$\chi^{2}$-test, df $=1,{ }^{*} p<005, \uparrow p<001$.

Table 6: Histamine-related cardiorespiratory disturbances after Induction of anaesthesla: subgroup analysis

the histamine release and the associated clinical disturbances were not necessarily immediate, occurring 20 min after the start of volume loading in 11 of the 18 detectable reactions to Haemaccel. In half of the remainder, rises earlier than 20 min were attributable to a carry-over effect from the curarising dose of alcuronium. Thirdly, though haemodynamic instabilities were the most consistent markers of untoward events, there was no characteristic direction of change: however, bradycardia $(39 \%)$ was more common than tachycardia $(17 \%)$, and hypotension $(50 \%)$ was more common than hypertension $(12 \%)$. The hypotensive affects attributable to histamine release were, of course, partly counteracted by the volume expansion: as one would expect, this tended to be more effective with Haemaccel than with Ringer, and was most effective when Haemaccel was given after antihistamine prophylaxis had attenuated the effects of any histamine - release. Fourthly, cutaneous reactions were seen in only 5 patients, and bronchospasm was seen in only 1.

Three findings demanded a cautious subgroup analysis (table 6)-the selection of malignant disease in logistic regression modelling; the imbalances of cardiovascular risk between the treatment groups (table 3); and the effects of antihistamines on histamine release, confounding their actions on histamine receptors. Patients with malignant disease seemed to be at twice the risk for clinically relevant histamine-related disturbances (RR 1.97 [0.9-4.3]) and at seven times the risk for life threatening ones (RR 7.23 $[0 \cdot 78-67 \cdot 1])$. Patients with cardiac and/or vascular disease showed only a slightly increased risk. The effects of the anti- $\mathrm{H}_{1} \mathrm{H}_{2}$ prophylaxis, however, were even stronger in the two subgroups than in the generality of patients in the study. Finally, anti- $\mathrm{H}_{1} \mathrm{H}_{2}$ reduced the incidence within each concentration band of histamine, thus demonstrating receptor-blocking effects after histamine release (table 6).

\section{Discussion}

Histamine release was very common during the whole preoperative period in circumstances that were carefully selected to represent everyday anaesthesia and surgery. It occurred at least once in every ten times that each anaesthetic drug was given and once in every three infusions for volume expansion. Clinical effects were detectable in 1 in 5 of the patients who received no antihistamines. This frequency contrasts sharply with the reported incidence of anaphylactoid reactions under anaesthesia of between 1 in 1000 and 1 in $10000 .^{1-5}$ Some say ${ }^{18}$ that direct non-immunological histamine release is largely innocuous and that any histamine detected in 
alarming reactions merely marks the co-release of more dangerous mediators. These claims must face the counterargument that there was only one clinically relevant histamine-related disturbance in the 115 patients given antihistamines, compared with 20 clinically relevant or life-threatening disturbances in the 116 given placebo. The clear effect of antihistamines in reducing histamine-related but not histamine-unrelated disturbances also validates the criteria by which the designations were made.

There are four reasons why such frequent and severe reactions have not previously been attributed to histamine. First, they have not been looked for as assiduously, with due attention to selection of a large and representative sample of everyday anaesthesia and surgery, to application of a successful double-blind design, and to the scrupulous blinded application and double-checking of predetermined criteria for designating episodes of histamine release and histamine-related disturbances. Second, the clinical manifestations of the episodes of histamine release were quite unlike those expected from the classic descriptions of allergy. There were almost no cutaneous signs, in contrast to findings in conscious subjects. ${ }^{23}$ Though haemodynamic instability was the most characteristic feature, there was no characteristic direction for the changes. If histamine had not been measured, many changes could well have been passed off as "normal" anaesthetic events and treated in the "normal" way. However, the occurrence of bradycardia in nearly half of the clinically detectable effects is a reminder (a) that bradycardia often accompanies the administration of atracurium ${ }^{22}$ (which has histamine-releasing properties), (b) that co-release of adenosine with histamine from the ischaemic heart can turn a potential histamine-induced tachycardia into a bradycardia, ${ }^{26}(c)$ that histamine is a potent coronary vasoconstrictor, ${ }^{13}$ and $(d)$ that bradycardia can be a marker of silent myocardial ischaemia. ${ }^{27}$ The third reason why severe histamine effects might have escaped notice is that Haemaccel- 35 was developed specifically to be safer than its predecessor, with less cross-linking material for producing histamine release. ${ }^{16}$ It proved safe for example in the Falklands war ${ }^{28}$ and in 600 unanaesthetised patients whom we have studied (in parallel to this study) during plasmapheresis. However, the delay of histamine release and its effects is consistent with a nonimmunological mechanism based on slow release and breakdown of cross-linking material from the gelatine hydrolysate. ${ }^{26}$ The severity of the reactions under anaesthesia and the increased risk in patients with malignant disease are consistent with evidence that cytokines $^{29}$ and exposure to anaesthetic drugs ${ }^{30}$ can prime mast cells and basophils to exaggerated release of histamine, in response not only to IgE but also to non-immunological triggers. The nature of this putative "pharmacological sensitisation" is still unclear, but its existence means that studies of histamine release with individual drugs in animals and conscious human beings may not be a reliable guide to their safety when they are given along with other drugs during anaesthesia and surgery. ${ }^{1-4}$

It was interesting, although not unexpected, ${ }^{7,22}$ that the antihistamines reduced the extent of histamine release as well as the incidence and severity of histamine-related disturbances. The effectiveness of dimetindene $\left(\mathrm{H}_{1}\right)$ and cimetidine $\left(\mathrm{H}_{2}\right)$ under the routine surgical conditions of this trial suggests that, rather than relying on allegedly "safe" drugs that may in fact be dangerous in certain combinations, we should consider the benefits of routine antihistamine prophylaxis.
Members of the trial group not listed as authors were Sir James Black, A Brouwer, H-J Bruer, W Dietz, M Ennis, $H$ Gajek, D Heintz-Bamberg, H J Hennes, B Kapp, M Künneke, M Marstaller, B McPeek, J Moss, St Otto, Ch Rehbock, D Rehn, K-P Reimund, H D Röher, M-S Rugeles, J Sattler, A Scherhag, M Teschner, R Zaczyk.

We are grateful for the support of Deutsche Forschungsgemeinschaft (Lo 199/14-2 to 16-2); Ciba-Geigy Zyma, Munich-Nyon; SK Beecham Pharma, Munich; and Behringwerke AG, Marburg/Lahn. The trial was performed under the auspices of the Permanent Working Party on Clinical Trials of the German Surgical Society.

\section{References}

1 Watkins J, Levy CJ. Guide to immediate anaesthetic reactions. London: Butterworth, 1988: 1-128.

2 Laxenaire $\mathrm{MC}$, Moneret-Vautrin. Le risque allergique en anesthesieréanimation (Coll Anesth Reanim, vol 17). Paris: Masson, 1990: 1-154.

3 Levy JH. Anaphylactic reactions in anesthesia and intensive care. Boston: Butterworth-Heinemann, 1992: 1-266.

4 Assem E-SK, ed. Allergic reactions to anaesthetics. Clinical and basic aspects (Monogr Allergy, vol 30). Basel: Karger, 1992: 1-236.

5 Fisher $\mathrm{McD} M$, Baldo BA. Anaphylactoid reactions during anaesthesia. Clin Anaesthesiol 1984; 2: 677-92.

6 Clarke RSJ. Prophylaxis of anaphylactoid reactions. Theor Surg 1988; 3: $142-44$.

7 Lorenz W, Doenicke A. $\mathrm{H}_{1}-+\mathrm{H}_{2}$-blockade: a prophylactic principle in anaesthesia and surgery against histamine-release responses of any degree of severity. Part I. N Engl Reg Allergy Proc 1985; 6: 37-57; Part II $1985 ; 6: 174-94$.

8 Lorenz W, Kubo K, Stinner B, et al. Studies on the effectiveness of $\mathrm{H}_{1-}+\mathrm{H}_{2}$-antagonist combinations to prevent life-threatening anaphylactoid reactions in anaesthesia and surgery: problems with selecting the animal model from clinical data and with "equi-effective" doses. Agents Actions 1992; 36: C231-237.

9 Neugebauer E, Holaday JW. Handbook of mediators in septic shock. Boca Raton: CRC Press, 1993: 1-565.

10 Lorenz W, Dietz W, Ennis M, Stinner B, Doenicke A. Histamine in anaesthesia and surgery: causality analysis. In: Uvnäs B, ed. Histamine and histamine antagonists. (Handb Exp Pharmacol, vol 97). Berlin: Springer Verlag, 1991: 385-439.

11 Dale HH. Croonian lectures on some chemical factors in the control of the circulation. Lancet 1929; i: 1285-90.

12 Oosting E, Neugebauer E, Keyzer JJ, Lorenz W. Determination of histamine in human plasma: the European external quality control study 1988. Clin Exp Allergy 1990; 20: 349-57.

13 Levi R, Rubin LE, Gross SS. Histamine in cardiovascular function and dysfunction: recent developments. In: Uvnas B, ed. Histamine and histamine antagonists. (Handb Exp Pharmacol, vol 97). Berlin: Springer Verlag, 1991: 347-83.

14 Chalmers TC. The quality of primary and secondary research and metaanalysis. Theor Surg 1989; 4: 98-99.

15 Lorenz W, Doenicke A, Messmer K, et al. Histamine release in human subjects by modified gelatin (Haemaccel ${ }^{*}$ ) and dextran: an explanation for anaphylactoid reactions observed under clinical conditions? $\mathrm{Br} \mathcal{F}$ Anaesth 1976; 48: 151-65.

16 Lorenz W, Doenicke A, Schöning B, Karges H, Schmal A. Incidence and mechanisms of adverse reactions to polypeptides in man and $\mathrm{dog}$. In: Hennessen W, ed. Joint WHO/IABS Symposium on the Standardization of Albumin, Plasma Substitutes and Plasmapheresis, Geneva, 1980 (Dev Biol Stand, vol 48). Karger, 1981: 207-34.

17 Lorenz W, Dick W, Junginger T, et al. Induction of anaesthesia and perioperative risk: influence of antihistamine $\mathrm{H}_{1}-+\mathrm{H}_{2}$-prophylaxis and volume substitution with Haemaccel-35 on cardiovascular and respiratory disturbances and histamine release-protocol of a controlled clinical trial. Theor Surg 1988; 3: 55-77.

18 Hobsley M, Moss J, Levi R, Clarke RSJ, Fisher M McD, Watkins J. Discussion forum about a protocol of a controlled clinical trial: induction of anaesthesia and perioperative risk. Theor Surg 1988; 3: 55-77.

19 Lorenz W, Doenicke A. Anaphylactoid reactions and histamine release by intravenous drugs used in surgery and anaesthesia. In: Watkins J, Ward AM, eds. Adverse response to intravenous drugs. London: Academic Press, 1978: 83-112.

20 Duda D, Lorenz W, Menke $\mathrm{H}$, et al. Histamine release during induction of anaesthesia and preparation for operation in patients undergoing general surgery: incidence and clinically severe cases. Agents Actions 1992; 36: C149-54.

21 Sitter $\mathrm{H}$, Lorenz $W$, Doenicke A. The clinical and biological signs of histamine release during induction of anaesthesia and preparation of the surgical patient: a farewell party for the classical manifestations of anaphylaxis. Agents Actions 1992; 36: C219-30.

22 Lorenz W, Sitter H, Stinner B, et al. Controlled clinical trials and 
cross-sectional studies with plasma histamine measurements and histamine receptor antagonists: solving the problem of preoperative $\mathrm{H}_{1}-+\mathrm{H}_{2}$-prophylaxis by asking new questions? Agents Actions 1991; 33: $197-230$.

23 Lorenz W, Doenicke A, Schöning B, Ohmann C, Grote B, Neugebauer E. Definition and classification of the histamine-release response to drugs in anaesthesia and surgery: studies in the conscious human subject. Klin Wschr 1982; 60: 896-913.

24 Lorenz W, Neugebauer E. Current techniques of histamine determination-fluorometric assays. In: Uvnäs $B$, ed. Histamine and histamine antagonists. (Handb Exp Pharmacol, vol 97). Berlin: Springer Verlag, 1991: 9-30.

25 Altman DG, Doré CJ. Randomisation and baseline comparisons in clinical trials. Lancet 1990; 335: 149-53.
26 Genovese A, Gross SS, Sakuma I, Levi R. Adenosine promotes histamine $\mathrm{H}_{1}$-mediated negative chronotropic and inotropic effects on human atrial myocardium. F Pharmacol Exp Ther 1988; 247: 844-49.

27 Mangano DT, Hollenberg M, Fegert G, et al. Perioperative myocardial ischemia in patients undergoing noncardiac surgery-I: incidence and severity during the 4 day perioperative period. $¥ A C C$ $1991 ; 17: 843-50$

28 William JG, Riley TRD, Moody RA. Resuscitation experience in the Falkland Islands campaign. BMF 1983; 286: 775-77.

29 Stellato C, Cirillo R, de Paulis A, et al. Human basophil/mast cell releasability. Anesthesiology 1992; 77: 932-40.

30 Dick W, Lorenz W, Heintz D, Sitter H, Doenicke A. Histamine release during induction of anaesthesia with nalbuphine or fentanyl. Anaesthetist 1992; 41: 239-47.

\section{Prospective study of endogenous tissue plasminogen activator and risk of stroke}

Paul M Ridker, Charles H Hennekens, Meir J Stampfer, JoAnn E Manson, Douglas E Vaughan

\section{Summary}

Few haematological or lipid risk factors have been identified for stroke, by contrast with coronary heart disease. To find out whether a marker of endogenous fibrinolytic function might be associated with stroke risk, we measured tissue plasminogen activator (tPA) antigen concentrations in baseline plasma samples from 88 healthy participants in the Physicians' Health Study who subsequently had first-ever strokes ( 71 thromboembolic, 12 haemorrhagic, 5 indeterminate) and from 471 participants who remained free of cardiovascular disease during 5 years of follow-up (controls).

Mean baseline tPA concentrations were significantly higher among men who later had strokes than in the controls (11 14 [SE 0.80$]$ vs $9.59[0.27] \mathrm{ng} / \mathrm{mL}, \mathrm{p}=0.03)$. The difference was largely due to an excess of abnormally high values among stroke cases. The age-adjusted relative risk for stroke among men with baseline tPA concentrations above the 95th percentile of the control distribution was $351(95 \% \mathrm{Cl}$ $172-7 \cdot 17, p=0$ 0006) for total stroke and 389 (1.83$826, p=0$ 0004) for thromboembolic stroke. These findings did not change substantially in analyses that also controlled for stroke risk factors (high blood pressure, body-mass index, smoking, presence of diabetes, and parental history of myocardial infarction) or the plasma lipid profile.

This prospective study shows that high concentrations of tPA antigen among apparently healthy men are independently associated with high risks of future stroke, especially thromboembolic stroke. This finding is consistent with the hypothesis that activation of the endogenous fibrinolytic system occurs years in advance of arterial vascular occlusion.

Lancet 1994; 343: 940-43

Divisions of Preventive Medicine (P M Ridker MD,

Prof C H Hennekens, J E Manson MD) and Cardiology (P M Ridker, D E Vaughan MD), Channing Laboratory (Prof M J Stampfer MD), and Center for Research in Thrombolysis (DE Vaughan), Department of Medicine, Brigham and Women's Hospital; Department of Ambulatory and Preventive Medicine, Harvard Medical School (Prof C H Hennekens); and Department of Epidemlology, Harvard School of Public Health (Prof M J Stampfer), Boston, Massachusetts, USA

Correspondence to: Dr Paul M Ridker, Brigham and Women's Hospital, 900 Commonwealth Avenue East, Boston, MA 02215, USA

\section{Introduction}

In most developed countries, stroke is the third commonest cause of death in adults, following coronary heart disease and cancer. However, by contrast with coronary heart disease, few important risk factors have been established for stroke; the exceptions are age, smoking, and high blood pressure. Lipid markers that are important in assessment of coronary risk have been far less reliable for identifying individuals at risk of stroke, even strokes of thromboembolic origin.

We have reported that in prospectively collected blood samples, high concentrations of endogenous tissue-type plasminogen activator (tPA), the primary mediator of intravascular fibrinolysis, among apparently healthy men are strongly associated with the risk of future myocardial infarction. ${ }^{1}$ On the basis of this finding, we have postulated that activation of the endogenous fibrinolytic system occurs several years before vascular occlusion and that the extent of this activation may serve as a marker for preclinical atherosclerosis. With cross-sectional data, others have found that tPA antigen concentrations correlate with carotid atherosclerosis; ${ }^{2}$ this observation raises the possibility that tPA antigen may also be a marker for risk of stroke. To test this hypothesis prospectively, we assessed whether high concentrations of tPA antigen among apparently healthy men are associated with the future occurrence of stroke.

\section{Patients and methods}

In this nested case-control study we analysed blood samples collected at baseline in the Physicians' Health Study, a randomised, double-blind, placebo-controlled trial of aspirin and $\beta$-carotene in the primary prevention of cardiovascular disease and cancer among 22071 US male physicians aged 40-84 years, who had not previously had myocardial infarction, stroke, transient ischaemic attack, or cancer. ${ }^{3}$ Before randomisation potentially eligible physicians were assigned to a regimen of active aspirin and $\beta$-carotene placebo in an 18 -week run-in to identify good compilers for long-term follow-up. During the run-in period, between 1982 and $1984,68^{\circ}{ }_{\text {o }}$ of the participants (14916 men) submitted plasma samples, which were stored at $-80^{\circ} \mathrm{C}$. Annual questionnaires on risk factors and disease outcomes have been mailed to and returned by these physicians or their families with a follow-up rate of $99.7 \%$ for morbidity and $100^{\circ}, 0$ for mortality.

Hospital records were requested for all reported cases of fatal and non-fatal stroke that occurred after randomisation. These records 